\title{
Groove Gap Waveguide in metallized 3D-printed plastic and in mechanized aluminium in $\mathrm{Ka}$ band
}

\author{
Adrián Tamayo-Domínguez, José-Manuel Fernández-González, Manuel Sierra-Pérez.
}

\begin{abstract}
This paper conducts a comparison between two different manufacturing technologies for a prototype in Groove Gap Waveguide. Both technologies are metallized 3D-printed plastic and mechanized aluminium. The prototype is a straight section with transitions to WR-28 that works in the frequency band from 28 to $30 \mathrm{GHz}$. The main properties of the technologies in terms of losses, weight and ease of manufacture are presented, as well as measurements for both prototypes together with simulations.
\end{abstract}

Keywords-3D-printed technology, groove gap waveguide, Ka band, manufacturing technologies, mechanized metal, metallized plastic.

\section{INTRODUCTION}

Recently, a new technology for microwave and submillimetric applications has emerged. This technology is Gap Waveguide, created and developed by Per-Simon Kildal [1]. The main objective of this technology is to provide very low losses while keeping a good integration capacity in complex designs and an easier manufacturing process. Gap Waveguide uses a metamaterial built with a periodic bed of nails that prevents the transmission of power in the transverse direction and confines the wave along the desired path. This structure generates a band of frequencies within only one mode can propagate inside the guide. There are several configurations in Gap Waveguide depending on the structure. In this work, the configuration chosen is Groove Gap Waveguide (GGW). A comparison with other technologies such as SIW is exposed in [2]. The objective of this paper is to compare over a straight section of GGW two different manufacturing technologies: metallized 3D-printed plastic and mechanized aluminium.

\section{MetalliZED PLASTIC VERSUS MECHANIZED ALUMININIUM}

Metallized 3D-printed technology provides great advantages over existing metal machining technology, which are: ease of manufacture, reduced costs, reduced lead times, reduced weight and increase in RF design flexibility. The critical part in the GGW structure is the one that includes the periodic lateral pins that can be printed and metallized very easily. Details about the printing technology and the copper plating can be found in [3].
In relation to the mechanizing technique, the final result and the manufacturing time are limited by the diameter of the drill and depends on the type of material. In this case, the material is an aluminium alloy that increments the strength of the material but reduces the conductivity to $\sigma=2.55 \cdot 10^{7} \mathrm{~S} / \mathrm{m}$, being $5.8 \cdot 10^{7}$ $\mathrm{S} / \mathrm{m}$ in the case of copper. Then, the prototype in aluminium will be more resistant but with higher losses than in metallized plastic.

\section{DESIGN OF THE GGW PROTOTYPE}

The base structure includes a bed of nails made of three rows of pins for the lateral metamaterial in a copper or aluminium surface that is covered by an aluminium plate. This structure is shown in Fig. 1 and the design parameters are provided in Table I.
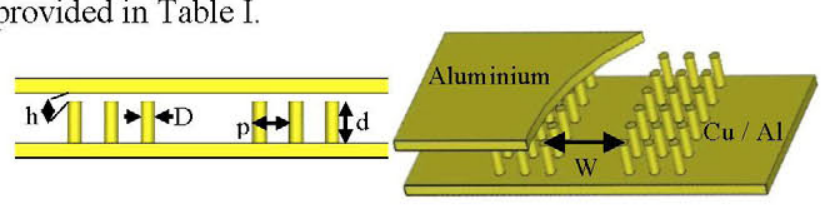

Fig. 1: GGW structure. Transversal view (left) and general view (right).

TABLE I. PARAMETERS OF GGW BASE STRUCTURE

\begin{tabular}{|c|c|c|c|}
\hline Parameter & Value & Parameter & Value \\
\hline $\mathrm{h}$ & $0.6 \mathrm{~mm}$ & $\mathrm{p}$ & $2.6 \mathrm{~mm}$ \\
\hline $\mathrm{D}$ & $1 \mathrm{~mm}$ & $\mathrm{~d}$ & $3 \mathrm{~mm}$ \\
\hline $\mathrm{W}$ & $8 \mathrm{~mm}$ & Materials & Copper/Aluminium \\
\hline
\end{tabular}

These dimensions are selected in order to ensure a good manufacturing result and to propagate a single mode in the desired band. The design for the transition to WR-28 is obtained from [4].

\section{FINAL DESIGNS AND RESULTS}

The total length of the final models from inputs to outputs is $34 \mathrm{~mm}$. The manufactured results are presented in Fig. 2.

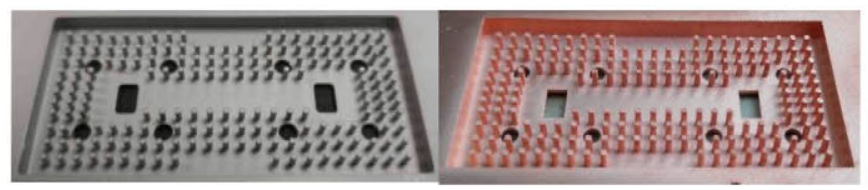

Fig. 2: Manufactured prototype in mechanized aluminium (left) and metallized 3D (right).

A comparison between measurement for both prototypes is depicted in Fig. 3, together with a simulation in CST considering the model with copper. 


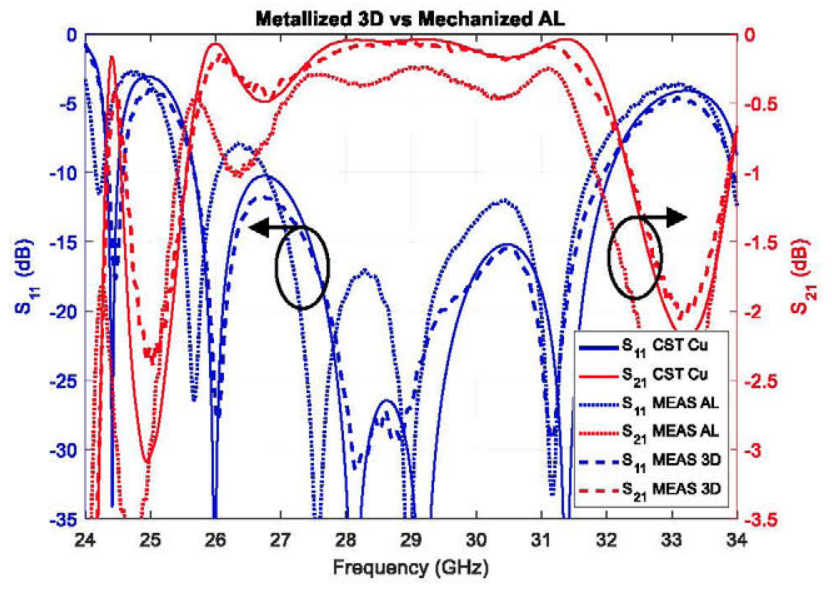

Fig. 3: Measurement and simulation of the GGW prototypes.

Measurement of the metallized 3D prototype fits very well with the simulation, as shown in Fig. 3. However, the model in aluminium presents a slightly displacement in frequency, which can be due to small deviations in the shape of the transition, and losses higher than expected. Losses are compared in Fig. 4.

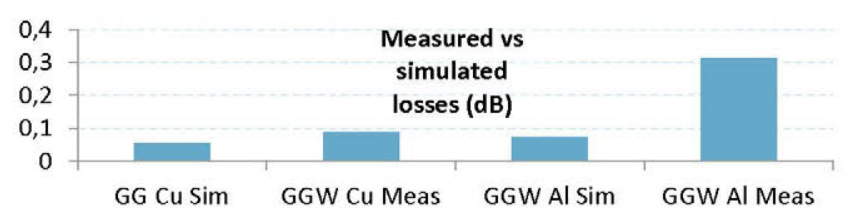

Fig. 4: Comparison of measured losses in metallized and mechanized models.

In Fig. 5, a detailed picture of transitions for both technologies is shown. The rounded corners in the aluminium prototype can be appreciated, as well a certain roughness of the material due to a sanding process applied after fabrication. We have resimulated the model considering the deviation in the transition shown in the top of Fig. 5 and an equivalent conductivity with the roughness shown in microphotographs in Fig. 6 and 7. The result obtained from the simulation, with an equivalent conductivity of $\sigma=0.1 \cdot 10^{7} \mathrm{~S} / \mathrm{m}$ is compared to the measurement in Fig. 8.

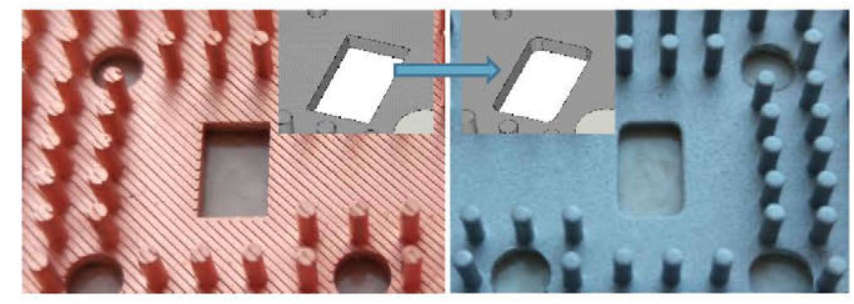

Fig. 5: Detailed structure of metallized (left) and mechanized (right) models.

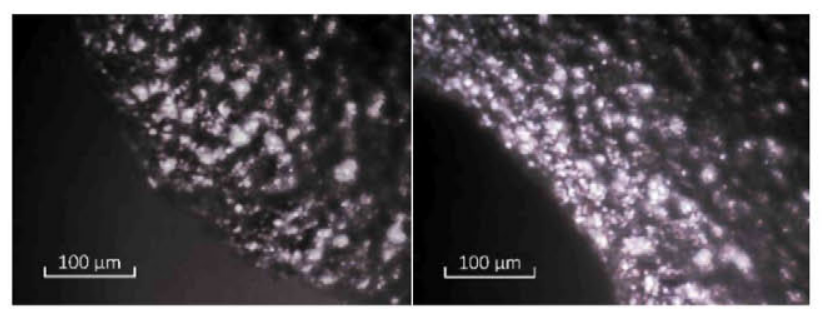

Fig. 6: Aluminium roughness in the pins (left) and in the corner of the transition (right). Mechanized model. Roughness $\simeq 15 \mu \mathrm{m}$.

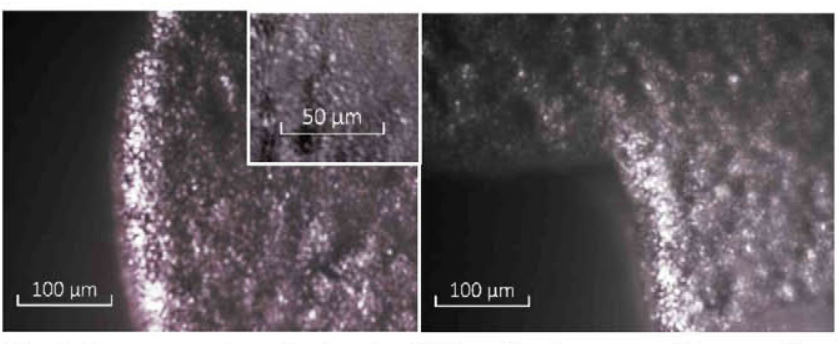

Fig. 8: Copper roughness in the pins (left) and in the corner of the transition (right). Metallized plastic model. Roughness $\simeq 3 \mu \mathrm{m}$.

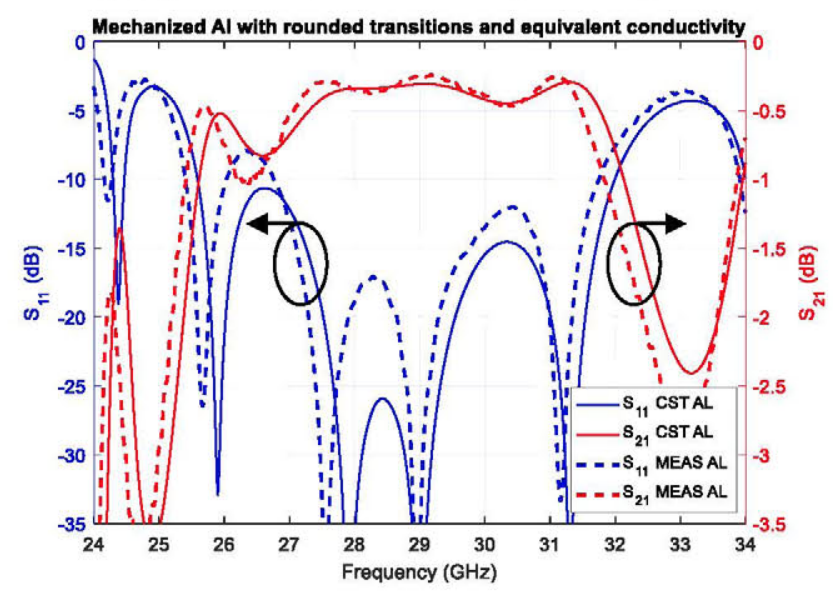

Fig. 8: Measurement and equivalent simulation of the aluminium prototype.

\section{Conclusions}

We have obtained a much better result with metallized 3D plastic than with mechanized aluminium because the conductivity is higher in copper and the manufacturing deviations are lower using printing technology. Moreover, the weight and cost of the printed prototype is considerably lower, although its strength is worse than in aluminium.

\section{ACKNOWLEDGMENT}

Simulations done in this work have been performed using CST Microwave Studio Suite 2016 under a cooperation agreement between Computer Simulation Technology (CST) and Technical University of Madrid.

\section{REFERENCES}

[1] P.-S. Kildal, "Three metamaterial-based gap waveguides between parallel metal plates for mm/submm waves," in Antennas and Propagation, 2009. EuCAP 2009. 3rd European Conference on, Mar. 2009, pp. 28-32.

[2] A. Tamayo, J.M. Fernández, M. Sierra, "Groove Gap Waveguide in 3DPrinted Technology for Low Loss, Weight and Cost Distribution Networks", IEEE transactions on microwave theory and techniques, unpublished.

[3] A. Tamayo, J.M. Fernández, M. Sierra, "Low Losses Printed Distribution Network Technologies for Planar Antennas in Ka Band". 11th European Conference on Antennas and Propagation (EuCAP), IEEE, 2017, in press.

[4] A. Berenguer, V. Fusco, D.E. Zelenchuk, D. Sánchez-Escuderos, M. Baquero-Escudero, V.E. Boria-Esbert. "Propagation characteristics of groove gap waveguide below and above cutoff'. IEEE Transactions on Microwave Theory and Techniques, 64(1), pp. 27-36, 2016. 